\title{
Lung involvement in brucellosis
}

\begin{abstract}
Brucella, a genus of Gram-negative bacteria is the causative agent of brucellosis. The disease, which can affect many organs and systems, is a major public health issue in developing countries where animal husbandry is a common practice. Brucellosis can involve almost any organ system, such as joint, heart, kidney, and particularly the reticuloendothelial system. Although respiratory system involvement is known, lung involvement is rarely seen. Non-specific clinical findings and complications complicate the diagnosis of brucellosis in patients with lung involvement. A 40-year-old male patient was admitted to our clinic with shortness of breath and fatigue. He had pneumosepsis and hyponatremia with a poor general status. Chest X-ray showed pleural effusion. His medical history revealed brucella 13 years prior. Blood and pleural effusion fluid tested positive for Rose-Bengtal and Wright agglutination tests $(1 / 320)$. The patient was diagnosed with brucella-related pneumonia and pleural effusion. This report highlights the necessity of careful diagnosis and treatment of brucella-related complications in brucellosis-endemic countries.
\end{abstract}

Keywords: brucellosis, rarelylunginfections, pneumonia
Volume 4 Issue 2 - 2017

Pınar Mutlu, Nihal Arzu Mirici, Oylum Hunerel

Chest Diseases Department, Canakkale Onsekiz Mart University, Faculty of Medicine, Turkey

Correspondence: : CanakkaleOnsekiz Mart University, Faculty of Medicine, Chest Diseases Department Kepez Yerleșkesi, Canakkale, Turkey, Email pinarmutlu78@yahoo.com

Received: March 05, 2017| Published: June 16, 2017

\section{Introduction}

Brucella, which is a genus of Gram-negative bacteria, is the cause of the infectious disease known as brucellosis. ${ }^{1}$ In humans, Brucella initially induce various polymorphonuclear responses in the submucosa following penetration to the conjunctiva, pharynx, lung, and epithelial cells in the skin. Bacteremia develops, unless host defense in lymph nodes overcomes infection. The incubation period usually ranges between 1.5 and 3 weeks between the infection and bacteremia. ${ }^{1}$ There are no specific or distinctive symptoms of Brucella infections. The clinical presentation is typically accompanied with shivering followed by rising fever, sweating, headache, malaise, fatigue, loss of weight, low back pain, and widespread body pain. The most common findings in the cases were fever, splenomegaly, hepatomegaly, lymphadenomegaly, and arthritis. ${ }^{2}$ About one-fourth of the patients with brucellosis have also respiratory symptoms. These symptoms mainly occur as a result of inhalation of contaminated aerosols or bacterial spread to the lungs through bacteremia. Bronchitis, bronchopneumonia, solitary or multiple nodules, lung abscess with a miliarypattern, hilar lymphadenopathy, and pleural effusion can be also seen. ${ }^{3}$ The diagnosis is confirmed with complete clinical findings, isolation of causative agent from blood and bone marrow cultures, and serological tests using standard tube agglutination positivity of $\geq 1 / 160 .{ }^{4}$ Herein, we report a rare case of brucellosis with lung and pleural involvement.

\section{Case report}

A 40-year-old male patient was admitted to our clinic with complaints of persistent cough for 10 days, phlegm, respiratory distress, fever at intervals, knee pain, and fatigue particularly increased for the past two days. During physical examination, the patient was conscious with poor orientation and cooperation, and was agitated and drowsy. His medical history was able to be obtained from his relatives due to his limited cooperation and orientation. He had a medical history of 20-packyears of smoking and brucellosis 13 years prior. He had a fever of $38.5^{\circ} \mathrm{C}$, heart rate was $113 \mathrm{bpm}$, blood pressure was $100 / 60 \mathrm{mmHg}$, and respiration rate was $32 / \mathrm{min}$. Lung auscultation showed bilateral, widespread crepitant rales in all zones of the lungs. Lung sounds were not present in the right basal lung, and dullness was detected with percussion. Cardiovascular examination findings were normal, except for tachycardia. Abdominal examination showed no signs of defense, rebound, or tenderness. Extremities were normal; however, circulatory impairment and cyanosis were present in the periphery. Laboratory test results were as follows: leukocyte $19,900 / \mathrm{mm}^{3}$, hemoglobin $13.7 \mathrm{~g} / \mathrm{dL}$, hematocrit $40 \%$, platelet count $270,000 / \mathrm{mm} 3$, erythrocyte sedimentation rate (ESR) $88 \mathrm{~mm} /$ hour, and C-reactive protein (CRP) was $15.1 \mathrm{mg} / \mathrm{dL}$. Arterial blood pressure analysis showed that $\mathrm{pH}$ was $7.29, \mathrm{PO}_{2}$ was $76 \mathrm{mmHg}, \mathrm{pCO}_{2}$ was $22 \mathrm{mmHg}, \mathrm{HCO}_{3}$ was $11 \mathrm{mmol} / \mathrm{L}$, and $\mathrm{satO}_{2}: 94 \%$. Biochemical analysis of blood showed a Na level of $122 \mathrm{mmol} / \mathrm{L}$, aspartate aminotransferase (AST) level of $306 \mathrm{IU} / \mathrm{mL}$, and alanine aminotransferase (ALT) of $143.6 \mathrm{IU} / \mathrm{mL}$. Metabolic acidosis was present in the arterial blood gas. A posteroanterior radiograph showed bilateral pneumonic infiltration and pleural effusion on the right side (Figure 1). Thoracic computed tomography (CT) showed multiple opacities and right-sided pleural effusion (Figure 2). Serum agglutination titer for Brucella was 1:320. Pleural fluid obtained on thoracentesis was consistent with exudate and hemorrhagic. Pleural fluid tested positive for Rose-Bengal test. Based on clinical and physical examination findings, the patient was diagnosed with brucellosis with lung and pleural involvement. The patient was initiated on ceftriaxone $2 \mathrm{~g}$ bid, doxycycline $100 \mathrm{mg}$ bid, and rifampicin $600 \mathrm{mg}$ once daily. His general condition improved on Day 15 of treatment and did not have fever for five days. He was discharged with the recommendation of outpatient follow-up visits. Doxycycline $100 \mathrm{mg}$ bid and rifampicin $600 \mathrm{mg}$ once daily treatment was scheduled to continue until two months (Figures $3 \& 4$ ). 


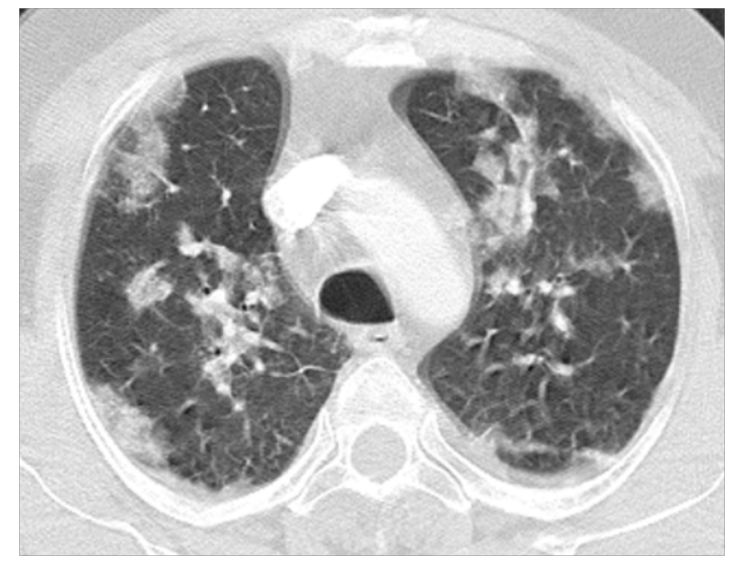

Figure I

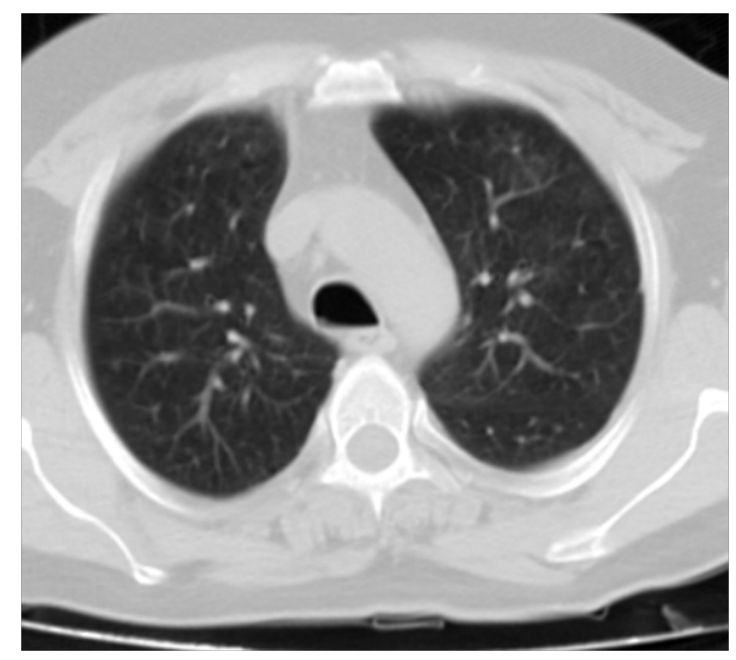

Figure 2

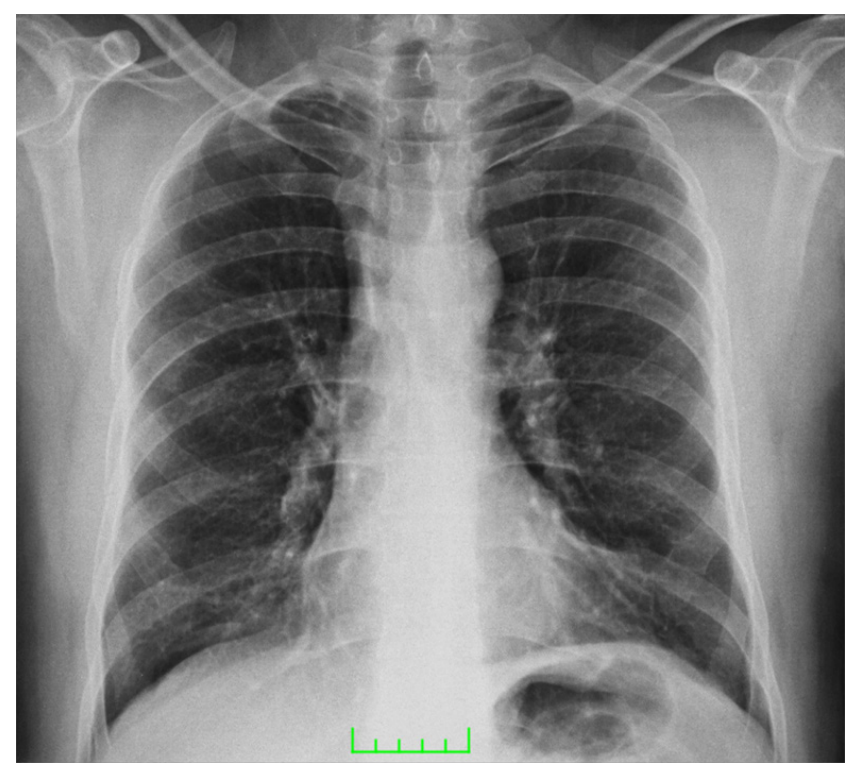

Figure 3

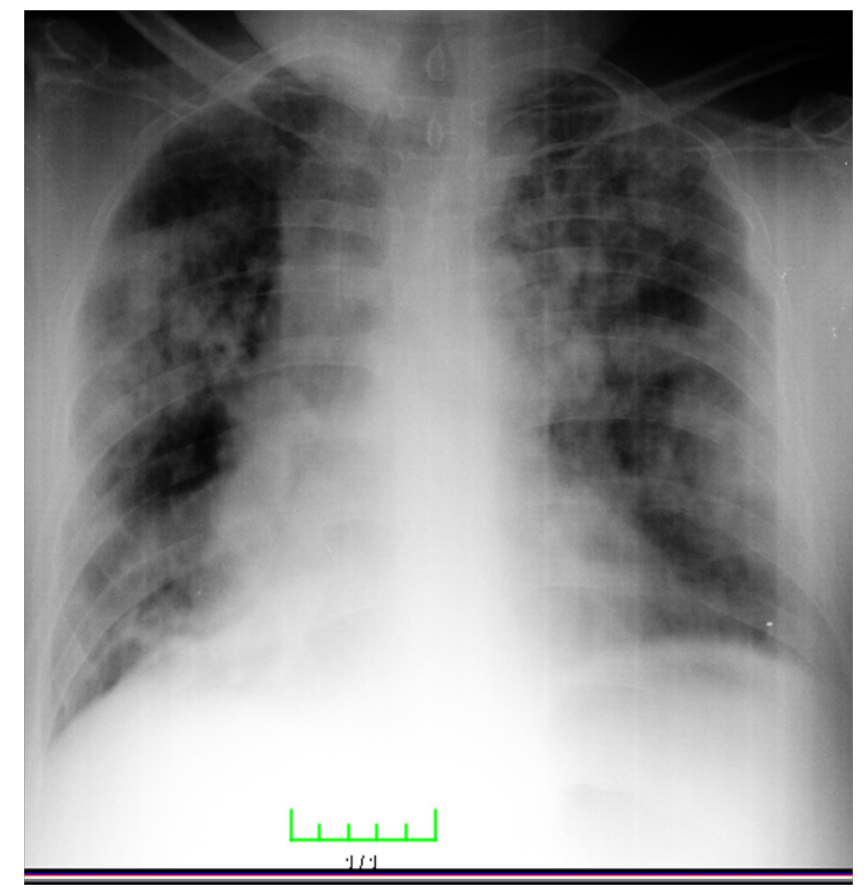

Figure 4

\section{Discussion}

Brucellosis remains to be an important health concern in many parts of the world. Every year, it causes thousands of individuals to have a chronic condition which occasionally results in mortality. ${ }^{5}$ It is a potent, Gram-negative, as porous, inactive, small coccobacilli bacterium. As it can easily reproduce in wet and humid environment, it can be produced in raw milk and milk products for a long time. It can be inactivated by boiling and pasteurization. It is transmitted by contact with infected animals or eating contaminated animal products. $^{6}$

Lung involvement in brucellosis is rare. ${ }^{7}$ It can be isolated as a respiratory system abnormality, or as a part of a sub acute systemic disease. Respiratory system symptoms can be seen as a result of inhalation or bacteremia leading to bacterial spread to lungs. Patients usually complain about non-specific or neuropsychiatric symptoms such as fever, sweating, fatigue, anorexia, loss of weight, and musclejoint pain. Our case had complaints of high fever at intervals and sweating, knee-joint pain, anorexia, expectorating cough, and fatigue. In addition, symptoms may vary depending on the localization of the involvement and include skin symptoms such as maculopapillary rash, muscle and skeletal system symptoms, painful sacroiliac, knee, hip, shoulder, hand, and wrist joints), hematological symptoms such as anemia, leucopenia, and thrombocytopenia, gastrointestinal symptoms such as nausea and vomiting, neurological symptoms, and cardiovascular symptoms. Mild-to-moderate increases in ESR and CRP, and a moderate increase in the kidney function tests can be observed. Similarly, our case had slightly elevated AST and ALT levels, and ESR and CRP levels.

Furthermore, dry cough can be seen in 10 to $33 \%$ of the patients. Lung involvement can present itself as flu-like symptoms, bronchitis, bronchopneumonia, pleural effusion, abscesses, pulmonary nodules, 
and hilar lymphadenopathy. The most frequent symptom of the lung involvement is non-productive cough. ${ }^{8}$ Symptoms are related to the respiratory airways in less than half of the patients with brucellosis who have abnormalities in the chest X-ray. Empyema, pleural effusion, interstitial pneumonia, hilar and paratracheal lymphadenopathyand pneumothorax are also rarely reported forms of involvement. A brucella agglutination titer of $\geq 1: 160$ indicatesan active infection. ${ }^{6}$ Similarly, our case tested positive for brucellosis based on pleural fluid and serological test results.

A multi-center study by Pappas reported that 37 (6.9\%) of a total of 450 patients with brucellosis had pulmonary involvement with varying clinical manifestations. ${ }^{7}$ The mean age of this patient group was 53 years with a female-to-male ratio of 1:2. In addition, 35 patients $(94.5 \%)$ had fever, $25(67.6 \%)$ had coughing symptoms, $10(27 \%)$ had sputum, and seven patients (19\%) had respiratory symptoms such as dyspnea. In addition, a retrospective study evaluated a large cohort of 1,028 patients with brucellosis. ${ }^{10}$ The mean age of the patients was 33.7 years, and the most common clinical and laboratory findings were fever, arthralgia, elevated CRP, and osteoarticular involvement. About $2 \%$ of the patients had coughing symptom, while seven $(0.7 \%)$ had pulmonary involvement in the form of pleurisy. In another prospective study, pulmonary involvement was seen in 11 of 110 patients with brucellosis $(10 \%) .{ }^{11}$ These patients had clinical symptoms including coughing, phlegm, and shortness of breath, and radiological symptoms including parenchymalnodules, lobar pneumonia, paratracheal lymphadenopathy, and pulmonary involvement such as pleural effusion. Treatment for brucellosis resulted in complete recovery of these symptoms. Similarly, our case recovered with treatment for brucellosis, as confirmed by chest X-ray and thoracic $\mathrm{CT}$.

\section{Conclusion}

Brucellosis is still a major infectious disease and continues to be a significant cause of morbidity in humans. It can be seen in almost every part of the world, particularly Mediterranean countries and can affect all individuals of all ages. In addition to muscle and joint involvement, pneumonia, parapneumonic effusions, empyema, and lung abscesses can be seen. We suggest that patients living in endemic regions should be followed carefully for possible pulmonary involvement and complications.

\section{Acknowledgments}

None.

\section{Conflicts of interest}

The authors declare that there is no conflict of interest.

\section{References}

1. Goldman L. Ausiello D Bruselloz. In: Unal S. Editor. Turkey: Cecil Medicine 23, baski, Ankara;2011. p. 2248-2251.

2. Topcu AW, Soyletir G, Doganay M. Brucella Turleri. In: Enfeksiyon Hastalıkları Ve Mikrobiyolojisi. Turkey: Istanbul;2008. p. 2237-2243.

3. Young EJ. Brucella species. Princeples and practice of infectious diseases Philadelphia. In: Inmandellgl, Bennettje, Dolin R, editors. UK: churcill livingstone; 2005. p. 2669-2674.

4. Aktas F, Senol E, Yetkin A, et al. Brucellosisda klinik ve laboratuvar bulgularının hastalık suresi ileiliskisi. Turk Mikrobiyol Cem Derg. 1994;24:164-169.

5. Alptekin N, Bilgic A. Brucellosisis. Fiziksel Tip ve Rehabilitasyon. 2003;3:97-105.

6. Johnson CC, Finegold SM. Pyogenic bacterial pneumonia, lung abscess and empyema. In: Murray JF, Nadel JA, editors. Textbook of Respiratory Medicine. $2^{\text {nd }} e d$, Philadelphia: WB Saunders Company, PAN;1994. p. 1036-1093.

7. Pappas G, Bosilkovski M, Akritidis N, et al. Brucellosis and the respiratory system. Clin Infect Dis. 2003;37:95-99.

8. Weinberg AN, Heller HM. Zoonotic and other bacterialpneumonias. In: Fishman AP, editor. Fishman's Pulmonary Diseases and Disorders $3^{\text {rd }} \mathrm{ed}$, USA: McGraw Hill, New York;1998:2413-2430.

9. Buzgan T, Karahocagil MK, Irmak H, et al. Clinical manifestations and complications in 1028 cases of brucellosis: a retrospective evaluation and review of the literature. Int J Infect Dis. 2010;14:469-478.

10. Hatipoglu CA, Bilgin G, Tulek N, Kosar U. Pulmonary involvement in brucellosis. J Infection. 2005;51(2):116-119.

11. Topcu AW, Soyletir G, Doganay M. Enfeksiyon Hastalıkları Ve Mikrobiyolojisi. Turkey: Istanbul; p. 2237-2243.

12. Johnson CC, Finegold SM. Pyogenic bacterial pneumonia, lung abscess and empyema. $2^{\text {nd }}$ ed. In: Murray JF, Nadel JA, editors. Textbook of Respiratory Medicine. PAN: Philadelphia;1994. p. 1036-1093. 